\title{
A Randomized Controlled Trial Examining the Effect of Aromatherapy Using the Damask Rose Essential Oil on Pre-operative Anxiety Levels
}

\author{
Mehran Farzaneh (iD) ${ }^{1}$, Vahid Zarean ${ }^{2}$, Ali Abbasijahromi (iD) ${ }^{3,}{ }^{*}$, Maryam Mohit (iD ${ }^{4}$, Mehdi Amirkhani \\ (iD) ${ }^{5}$,Zohreh Badiyepeymaiejahromi (iD ${ }^{6}$, Hamid Reza Dowlatkhah ${ }^{7}$ and Hamed Hojati ${ }^{8}$ \\ ${ }^{1}$ Master of Nurse Anesthesia Education, Ahvaz Jundishapur University of Medical Sciences, Ahvaz, Iran \\ ${ }^{2}$ Bachelor of Nurse Anesthesia, Jahrom University of Medical Sciences, Jahrom, Iran \\ ${ }^{3}$ Anesthesiology and Intensive Care Department, School of Nursing and Paramedical Sciences, Jahrom University of Medical Sciences, Jahrom, Iran \\ ${ }^{4}$ Master of Surgical Technology, Shiraz University of Medical Sciences, Shiraz, Iran \\ ${ }^{5}$ Department of Health in Disasters and Emergencies, School of Management and Medical Informatics, Shiraz University of Medical Sciences, Shiraz, Iran \\ ${ }^{6} \mathrm{PhD}$ of Nursing, Faculty of Nursing, Jahrom University of Medical Sciences Jahrom, Iran \\ ${ }^{7}$ Department of Statistics, Jahrom University of Medical Sciences, Jahrom, Iran \\ ${ }^{8}$ Jahrom University of Medical Sciences, Jahrom, Iran \\ "Corresponding author: Anesthesiology and Intensive Care Department, School of Nursing and Paramedical Sciences, Jahrom University of Medical Sciences, Jahrom, Iran. Tel: \\ +98-9173914974, Email: aliabbasijahromi@yahoo.com
}

Received 2021 June 20; Revised 2021 October 01; Accepted 2021 November 28.

\section{Abstract}

Background: Non-pharmacological care interventions like aromatherapy can be cost-effective and efficient ways to reduce anxiety and adverse results before surgery.

Objectives: In this study, the efficacy of aromatherapy on pre-operative anxiety in patients undergoing Percutaneous Nephrolithotomy (PCNL) referring to Peymaniyeh Hospital in Jahrom-Iran was the main goal.

Methods: This controlled-randomized trial was conducted on 38 patients that were randomly assigned to two groups: Control and Aromatherapy (Rosa damascena). The anxiety levels were recorded for all two groups the night before the surgery. On the day of surgery and after re-communication, patients were approached in a pre-operative holding area, and the intervention was performed. Data were collected over 11 months from June 2015 to May 2016.

Results: The statistically significant difference after the intervention between the control and intervention groups indicated that Aromatherapy with Rosa damascene reduced the patient's anxiety.

Conclusions: This survey prepares evidence for the use of Damask rose as an anti-anxiety intervention. Using Damask rose as a nursing intervention helps nurses provide individualized care and helps patients control their anxiety.

Keywords: Complementary Therapy, Anxiety, Aromatherapy, Rosa Damascene

\section{Background}

Pre-operative anxiety is one of the most common mental problems and disorders before surgery $(1,2)$. The patients experience anxiety before surgery because of a variety of reasons, such as fear of strangers, waking, death, and the aggressive nature of the surgery (3). The findings show that between $11 \%$ and $80 \%$ of adults experience preoperative anxiety under surgeries (4). Super-Anxiety before surgery can cause psychological reactions, increase the prevalence of nausea and vomiting after surgery, and increase the need for painkillers and anesthesia in individuals $(5,6)$.

Traditional medications such as benzodiazepines, which have many side effects, are commonly used to treat anxiety before surgery (6). Due to the side effects of these drugs, methods that have minimal side effects should be used to reduce the patient's anxiety and relaxation $(7,8)$. Today, in many medical centers, the use of complementary and alternative therapies is expanding due to their low risk, cost-effectiveness, ease, and limited side effects in nursing care. One of the methods of complementary medicine is aromatherapy (9-11). Aromatherapy is the controlled use of aromatic oils to maintain and promote physical and mental health, which has been considered part of complementary medicine in nursing in other countries such as the United Kingdom, Germany, Canada, and the United States (12).

These aromatic molecules can affect the hypothalamus, the autonomic nervous system, and the endocrine system, which ultimately improves peripheral blood cir- 
culation, helps regulate blood pressure and respiration. Eventually, all of these things lead to a reduction in stress and anxiety (13). Rosa damascena originates in the Middle East and is used in ornamental, food, and medicinal plants (14). It is also known as one of the most important aromatic plants in the genus Rosaceae (15). Damask roses are currently found in the world, especially in Iran, India, Turkey, Europe, and Bulgaria, and are also known as the king of flowers (16-18).

\section{Objectives}

Given the benefits of aromatherapy, the importance of surgical anxiety, and the limited number of studies that have examined inhalation aromatherapy with Damask rose, particularly in percutaneous nephrolithotomy (PCNL) patients, the research team reviewed this study intending to determine the effect of aroma intervention on the severity of pre-operative anxiety.

\section{Methods}

This double-blind randomized trial was performed according to Figure 1 from June 2015 to May 2016. A study by Kanani et al. (19) was used to estimate the sample size, and the following data were extracted: group 1 (mean \pm SD) $=$ $45.6 \pm 11.8$, group $2($ mean $\pm S D)=36 \pm 8.9$. As a result, a total of 38 patients under PCNL surgery were randomly divided into control and aromatherapy (19 in each group) using a power formula with $\alpha=0.05$, power of $80 \%$, and effect size $=92 \%$. Both researcher and the patients were blinded to the allocation of treatment. Randomization numbers were created from the random number table. The consent was taken from the patients.

PCNL patients with the following criteria were included in the study: lack of cancer and chronic pains, no allergies to fragrance substances, no proven problems with the sense of smell, non-addiction to drugs and alcohol, psychological health, interest in the scent of Damask roses, and at least primary-school education.

Two questionnaires were used to collect information: (1) Demographic Characteristics (sex, age, education) and (2) Spielberger STAI. The STAI was developed by Spielberger in 2009 and asked about general feelings and the level of anxiety. This scale evaluates the quality of tension, apprehension, and anger. The Spielberger STAI measures overt anxiety (a personality characteristic) and covert anxiety (anxiety level at a given moment). The Spielberger inventory consists of two 20 item questionnaires, one for overt and one for covert anxiety. Each of the 20 items is a statement, and the subject must indicate the statement's applicability as being either not at all, somewhat, moderately so, or very much so. Mahram (20) measured the reliability of this scale in a normative statistical population through Cronbach's alpha ( $\alpha=0.9452)$.

Demographic variables and the incidence of anxiety were recorded for all two groups the night before the surgery. On the day of surgery and after re-communication, Patients were approached in a preoperative holding area.

In the intervention group, the cotton balls were stained with three drops of Rosa damascene oil and placed at a distance of $10 \mathrm{~cm}$. Patients were asked to inhale cotton balls for 30 minutes. In the control group, all of the mentioned measures were performed using distilled water. The severity of anxiety was measured five minutes after the intervention. Also, patients' family members were asked not to meet the participants in the intervention's times. All nursing and medical procedures were similar for both groups. The comparison of statistical data was performed using SPSS version 16 at the significance level of $\mathrm{P}<$ 0.05 .

\section{Results}

In the intervention group, the mean age of the participants was $49.21 \pm 10.63,63.6 \%$ had a diploma's degree, and $52 \%$ were non-native residents of Jahrom, Iran and in the control group, the mean age of the participants was 47.74 $\pm 15.47,66.7 \%$ had a bachelor's degree, and $53.8 \%$ were native residents of Jahrom, Iran. None of the participants were smokers. Demographic variables showed no significant difference between the groups according to the results of the $t$-test and chi-square. The subjects in the two groups were homogenous concerning demographic variables $(\mathrm{P}>0.05)$.

There was no significant difference in the overt anxiety scores before the intervention between the groups according to the independent $t$-test $(\mathrm{P}=0.050)$. After the intervention, there was a statistically significant reduction in the mean overt anxiety between the groups $(\mathrm{P}<0.001)$ (Table 1). Before the intervention, the mean score of covert anxiety was compared between the two groups, and there was no significant difference according to the independent $t$-test ( $\mathrm{P}=0.361$ ). Comparison of the mean scores of the covert anxiety between the two groups before and after the intervention showed a significant difference $(\mathrm{P}<0.001)$ (Table 2).

The lack of a significant difference in the mean scores of anxiety before the intervention showed similar patients. The statistically significant difference after the intervention between the control and intervention groups indicated that Aromatherapy with Rosa damascene reduced the patient's anxiety. 


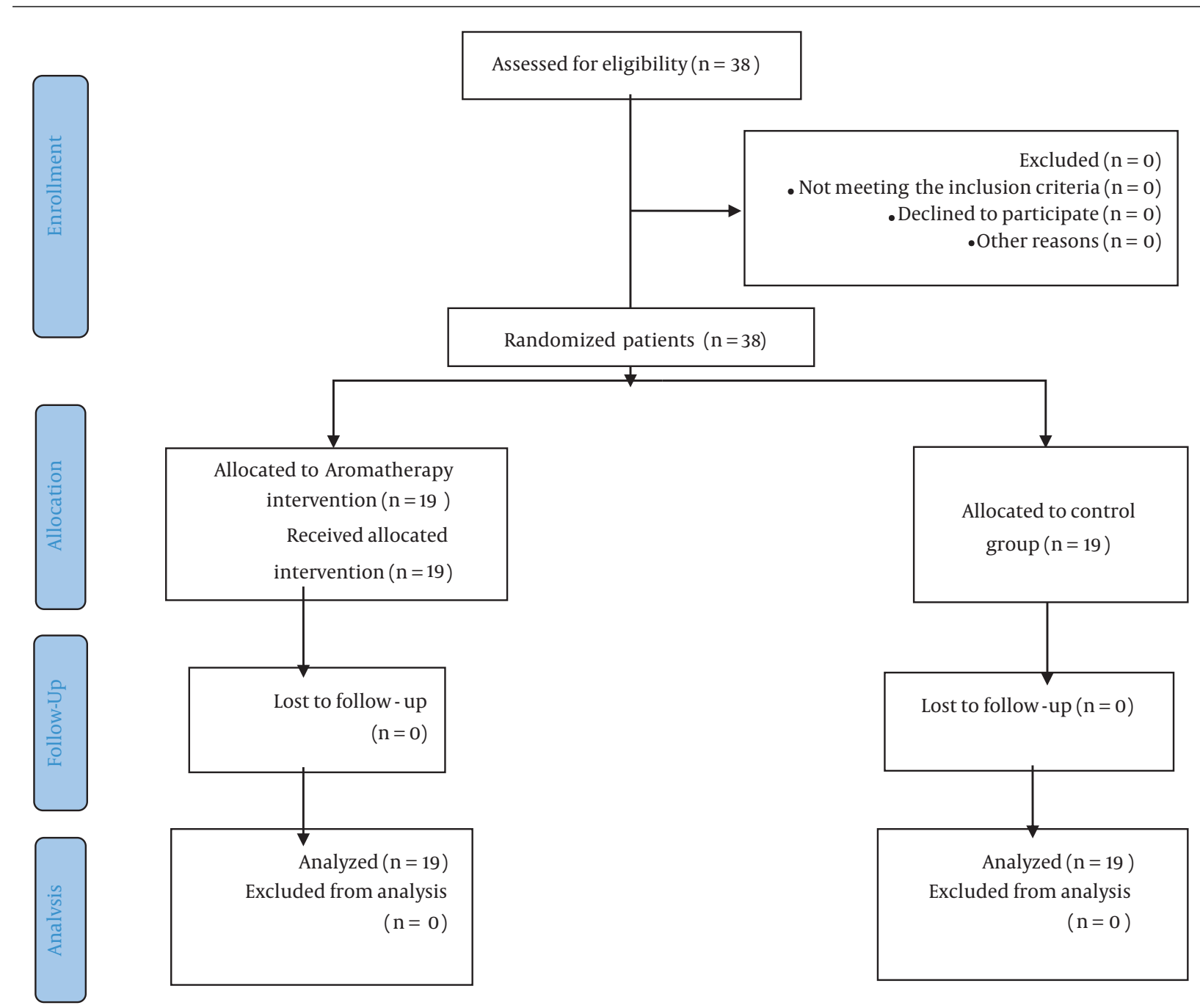

Figure 1. The Consort flow chart of the randomized trial.

\begin{tabular}{|c|c|c|c|}
\hline \multirow{2}{*}{ Anxiety } & \multicolumn{2}{|c|}{ Group } & \multirow{2}{*}{ P-Value } \\
\hline & Control & Intervention & \\
\hline \multicolumn{4}{|l|}{ Overt } \\
\hline Pre & $28.352 \pm 5.17$ & $24.823 \pm 4.94$ & 0.050 \\
\hline Post & $29.529 \pm 5.71$ & $21.647 \pm 5.29$ & $<0.001$ \\
\hline
\end{tabular}

${ }^{\mathrm{a}}$ Values are expressed as Mean $\pm \mathrm{SD}$.

Also, error bar diagrams emphasize the present finding by comparing overt and covert anxiety between the control and the intervention groups (Figures 2 and 3 ). Hence, the effect of Rosa damascene in reducing the patient's anxiety becomes more perspicuous.

\section{Discussion}

Since nurses spend more time with patients, they can assess their anxiety and use non-pharmacological techniques such as aromatherapy with Rosa damascene -an inexpensive and non-invasive tool-if needed. The use of aro- 


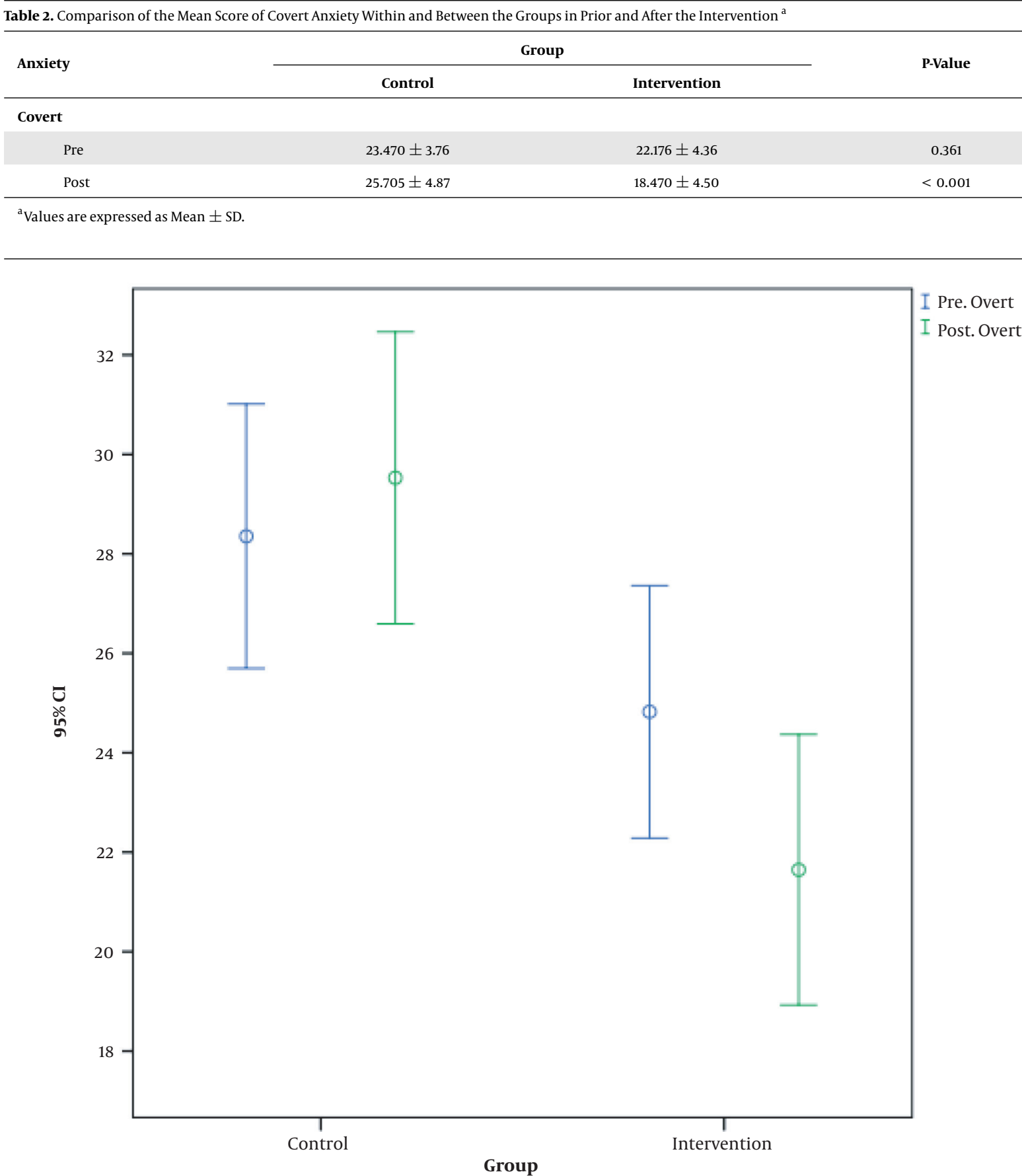

Figure 2. Error bar diagram of overt anxiety prior and after the intervention between the groups.

matherapy with Rosa damascene as a nursing intervention is the focus of nursing care to improve health indicators (21).

Our study showed that the level of overt and covert anxiety decreased significantly after aromatherapy with the
Rosa damascene. In this regard, Dehkordi et al. showed that the rate of depression, anxiety, and stress has been significantly reduced by using aromatherapy with Damask rose oil (22). Nasiri et al. found that Damask rose inhalation and massage forms could reduce the severity of pain 


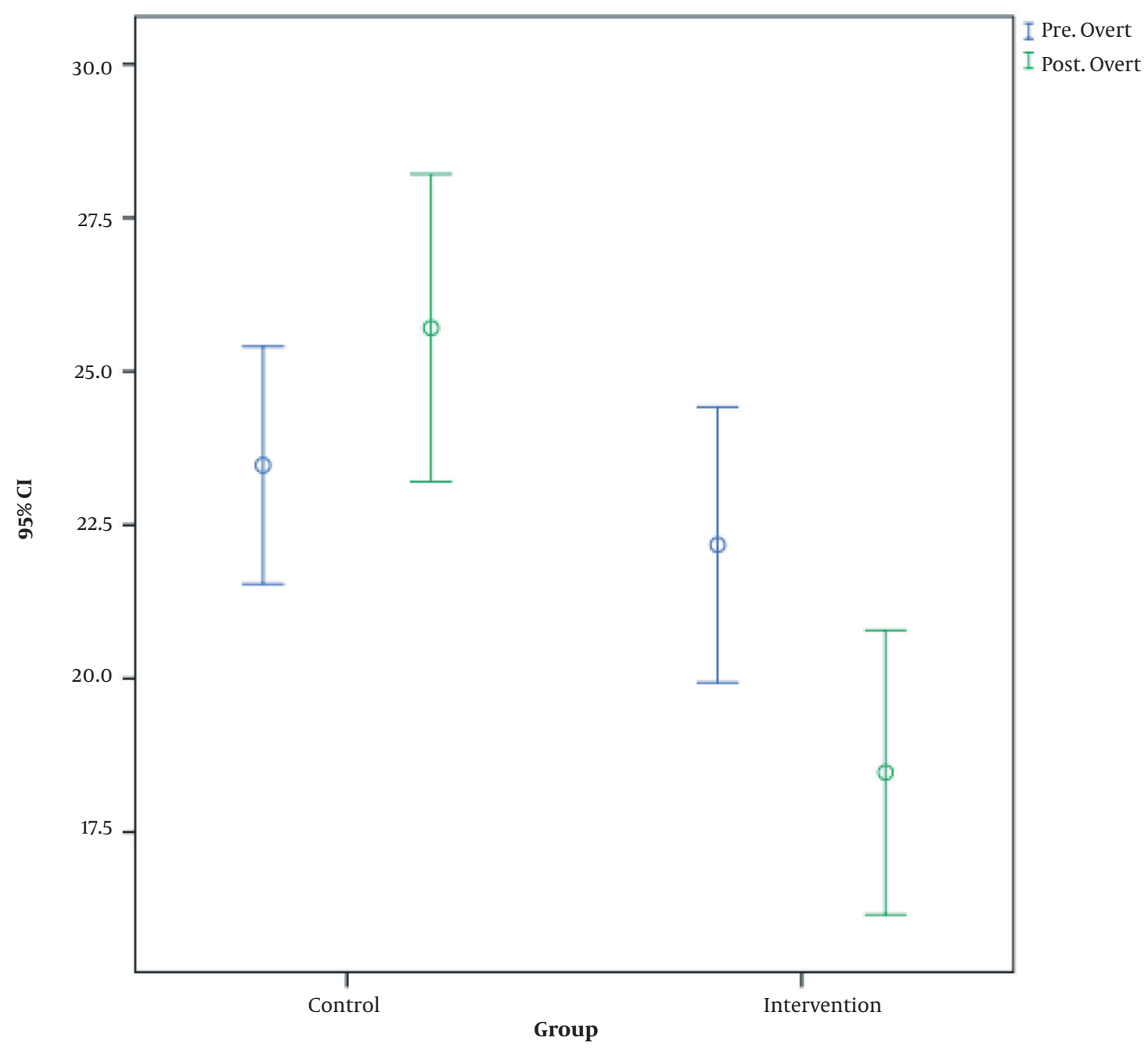

Figure 3. Error bar diagram of covert anxiety prior and after the intervention between the groups.

in adults (23). Hamdamian et al. stated that aromatherapy with R. Damascena reduced pain and anxiety in the first stage of labor (24). Also, several clinical trials have reported analgesic effects of Damask rose in various forms of administration, especially aromatherapy (25-27), which supported the results of our study.

However, some studies have reported results contrary to the present study. In a systematic review study, it was shown that there was no reduction in postoperative pain intensity compared to the control group after administration of Damask rose and ginger. The lack of reduction in postoperative pain can be attributed to combining Damask rose and ginger (28). Results of a study by Graham et al. in Australia showed that aromatherapy had not been effective in reducing the patients' anxiety under radiother- apy. Researchers believe that this increase in anxiety is due to the association between a specific smell and the anxious experience of radiotherapy (29).

\subsection{Conclusions}

Our results suggest that Damask rose intervention could lead to significantly reduced anxiety levels. Also, aromatherapy with Damask rose is an easy, simple, safe, and effective method that can be used to reduce physiological responses caused by anxiety. This intervention is economically feasible for patients, and nurses can use it for individualized care to achieve relaxation for its short-term benefits. 


\section{Footnotes}

Authors' Contribution: M. F., V. Z., and A. AJ. developed the original idea, wrote the manuscript, and is a guarantor. Z. BJ., M. M., and M. A. contributed to the development of the protocol and prepared the manuscript. H. H. and HR. D. participated in designing the evaluation, performed parts of the statistical analysis, and helped to draft the manuscript. All of the authors accepted responsibility for the entire content of this submitted manuscript and approved submission.

Clinical Trial Registration Code: Iranian Registry of Clinical Trial: IRCT2016020414049N3.

Conflict of Interests: The authors declare no conflict of interests.

Ethical Approval: This paper presents the results of a research project approved by the Jahrom University of Medical Sciences, Ethics Committee code of IR.JUMS.REC.1394.180.

Funding/Support: The support from the Jahrom University of Medical Sciences, Ethics Committee code of IR.JUMS.REC.1394.180 and the assistance of the ViceChancellor of Jahrom University of Medical Sciences, who provided financial support for this project, are gratefully acknowledged.

Informed Consent: The consent was taken from the patients.

\section{References}

1. Beyliklioglu A, Arslan S. Effect of Lavender Oil on the Anxiety of Patients Before Breast Surgery.J Perianesth Nurs. 2019;34(3):587-93. doi: 10.1016/j.jopan.2018.10.002. [PubMed:30660371].

2. Rajai N, Sajadi SA, Teymouri F, Zareiyan A, Siavoshi S, Malmir M. The Effect of Aromatherapy with Lavender Essential Oil on Anxiety and Stress in Patients Undergoing Coronary Artery Bypass Graft Surgery. JundishapurJ Chronic Dis Care. 2016;5(4). doi: 10.17795/jjcdc-34035.

3. Arı M, Yılmaz E. Impact of Preoperative Anxiety on Postoperative Constipation. Turk J Colorectal Dis. 2016;26(2):39-46. doi: 10.4274/tjcd.72677.

4. Bansal T, Joon A. A comparative study to assess preoperative anxiety in obstetric patients undergoing elective or emergency cesarean section. Anaesth Pain Intensive Care. 2019:25-30.

5. Abadi F, Abadi F, Fereidouni Z, Amirkhani M, Karimi S, Najafi Kalyani M. Effect of Acupressure on Preoperative Cesarean Section Anxiety. J Acupunct Meridian Stud. 2018;11(6):361-6. doi: 10.1016/j.jams.2018.07.001. [PubMed: 29990586].

6. Jaruzel CB, Gregoski M, Mueller M, Faircloth A, Kelechi T. Aromatherapy for Preoperative Anxiety: A Pilot Study. J Perianesth Nurs. 2019;34(2):259-64. doi: 10.1016/j.jopan.2018.05.007. [PubMed: 30205934].

7. Franco L, Blanck TJ, Dugan K, Kline R, Shanmugam G, Galotti A, et al. Both lavender fleur oil and unscented oil aromatherapy reduce preoperative anxiety in breast surgery patients: a randomized trial.J Clin Anesth. 2016;33:243-9. doi: 10.1016/j.jclinane.2016.02.032. [PubMed: 27555173].

8. Abbasijahromi A, Hojati H, Nikooei S, Jahromi HK, Dowlatkhah HR, Zarean V, et al. Compare the effect of aromatherapy using lavender and Damask rose essential oils on the level of anxiety and severity of pain following C-section: A double-blinded randomized clinical trial. J Complement Integr Med. 2020;17(3). doi: 10.1515/jcim-2019-0141. [PubMed: 31730539].

9. Farzaneh M, Bahmanjahromi A, Abbasijahromi A, Zarean V, Nikooei S. Comments on "The Comparison of the Effect of Two Complementary Methods as Music and Massage Therapy on Postoperative Acute Pain A Randomized, Clinical Trial”. Iran Red Crescent Med J. 2018;21(1). doi: 10.5812/ircmj.62036.

10. Farzaneh M, Abbasijahromi A, Saadatmand V, Parandavar N, Dowlatkhah HR, Bahmanjahromi A. Comparative Effect of NatureBased Sounds Intervention and Headphones Intervention on Pain Severity After Cesarean Section: A Prospective Double-Blind Randomized Trial. Anesth Pain Med.2019;9(2). e67835. doi: 10.5812/aapm.67835. [PubMed: 31341820]. [PubMed Central: PMC6614917].

11. Gharaee R, Saghi N, Nasiri M, Jafari Kheyrabadi A. [A comparative study on the effects of aromatherapy with orange and Citrus aurantium extracts on sleep quality in patients with acute coronary syndrome]. Koomesh J. 2020;22(2):275-81. Persian. doi: 10.29252/koomesh.22.2.275.

12. Givi F, Esmaeili R, Mojab F, Nasiri M, Shadnoush M. [Effects of aromatherapy using lavender on the quality of sleep of hospitalized elderly]. Koomesh J. 2019;21(2):254-61. Persian.

13. Jazini dorcheh S, Dehghan Abnavi S, Mousavi E, Zabihirad J. Effect of Aromatherapy with Lavender Extract on Occupational Stress among Operating Room Staff. J Ilam Univ Med Sci. 2020;28(2):32-7. doi: 10.29252/sjimu.28.2.32.

14. Nunes H, Miguel MG. Rosa damascena essential oils: a brief review about chemical composition and biological properties. Trends Phytochem Res. 2017;1(3):111-28.

15. Nasery M, Hassanzadeh MK, Najaran ZT, Emami SA. Rose (Rosa $\times$ damascena Mill.) Essential Oils. Essential Oils in Food Preservation, Flavor and Safety:. Elsevier; 2016. p. 659-65. doi: 10.1016/b978-0-12416641-7.00075-4.

16. Mahboubi M. Rosa damascena as holy ancient herb with novel applications. J Tradit Complement Med. 2016;6(1):10-6. doi: 10.1016/j.jtcme.2015.09.005. [PubMed: 26870673]. [PubMed Central: PMC4737971].

17. Boskabady MH, Shafei MN, Saberi Z, Amini S. Pharmacological Effects of Rosa Damascena. Iran J Basic Med Sci. 2011;14(4):295-307. doi: 10.22038/ijbms.2011.5018.

18. Nayebi N, Khalili N, Kamalinejad M, Emtiazy M. A systematic review of the efficacy and safety of Rosa damascena Mill. with an overview on its phytopharmacological properties. Complement Ther Med.2017;34:12940. doi: 10.1016/j.ctim.2017.08.014. [PubMed: 28917365].

19. Kanani M, Mazloum SR, Emami A, Mokhber N. The effect of aromatherapy with orange essential oils on anxiety in patients undergoing hemodialysis. J Sabzevar Univ Med Sci. 2012;19(3 (65)):249-57.

20. Mahram B. [The guideline for state and trait anexiety test of Spielberger and the instruction for its explanation based on normality test research in Mashahad]. Tehran: Allameh Tabatabaiee University; 1993. Persian.

21. Daneshpajooh L, Najafi Ghezeljeh T, Haghani H. Comparison of the effects of inhalation aromatherapy using Damask Rose aroma and the Benson relaxation technique in burn patients: A randomized clinical trial. Burns. 2019;45(5):1205-14. doi: 10.1016/j.burns.2019.03.001. [PubMed: 30948278].

22. Dehkordi AK, Tayebi A, Ebadi A, Sahraei H, Einollahi B. Effects of Aromatherapy Using the Damask Rose Essential Oil on Depression, Anxiety, and Stress in Hemodialysis Patients: A Clinical Trial. Nephro-Urol Mon. 2017;9(6). doi: 10.5812/numonthly.60280.

23. Nasiri M, Torkaman M, Feizi S, Bigdeli Shamloo MB. Effect of aromatherapy with Damask rose on alleviating adults' acute pain severity: A systematic review and meta-analysis of randomized controlled trials. Complement Ther Med. 2021;56:102596. doi: 10.1016/j.ctim.2020.102596. [PubMed: 33197671].

Nephro-Urol Mon. In Press(In Press):e116696. 
24. Hamdamian S, Nazarpour S, Simbar M, Hajian S, Mojab F, Talebi A. Effects of aromatherapy with Rosa damascena on nulliparous women's pain and anxiety of labor during first stage of labor. J Integr Med. 2018;16(2):120-5. doi: 10.1016/j.joim.2018.02.005. [PubMed: 29526235].

25. Amini R, Alizadeh F. Investigating musical effects and aromatherapy on anxiety and pain in patients undergoing surgery. Indian J Forensic Med Toxicol. 2018;12(4):170. doi:10.5958/0973-9130.2018.00219.0.

26. Babatabar Darzi H, Vahedian-Azimi A, Ghasemi S, Ebadi A, Sathyapalan T, Sahebkar A. The effect of aromatherapy with rose and lavender on anxiety, surgical site pain, and extubation time after openheart surgery: A double-center randomized controlled trial. Phytother Res. 2020;34(10):2675-84. doi: 10.1002/ptr.6698. [PubMed: 32267031].

27. Chughtai A, Navaee M, Alijanvand MH, Yaghoubinia F. Comparing the effect of aromatherapy with essential oils of Rosa damascena and lavender alone and in combination on severity of pain in the first phase of labor in primiparous women. Crescent J Med Biol Sci. 2018;5(4):312-9.

28. Arruda APN, Zhang Y, Gomaa H, Bergamaschi CC, Guimaraes CC, Righesso LAR, et al. Herbal medications for anxiety, depression, pain, nausea and vomiting related to preoperative surgical patients: a systematic review and meta-analysis of randomised controlled trials. BMJ Open. 2019;9(5). e023729. doi: 10.1136/bmjopen-2018-023729. [PubMed: 31129571]. [PubMed Central: PMC6538060].

29. Graham PH, Browne L, Cox H, Graham J. Inhalation aromatherapy during radiotherapy: results of a placebo-controlled doubleblind randomized trial. J Clin Oncol. 2003;21(12):2372-6. doi: 10.1200/JCO.2003.10.126. [PubMed: 12805340]. 